\title{
Editorial: Regional responses to Higher Education world-wide challenges
}

\author{
Luigi F. Donà dalle Rose \\ Editor
}

Anna Serbati

Assistant Editor

doi: http://dx.doi.org/10.18543/tjhe-5(1)-2017pp13-17

The world population is rich in diversity and represents a great value. Each of the several regions follows its own customs and traditions, diverse paths of development, adapts itself to quite different natural environments and builds socio-political institutions. Nevertheless, in a global world, the wind of innovation and the urge of reforms in general, and in higher education in particular, are now almost universal. The world-wide mobility of people regards - among many others - international students, both the students doing the entire degree abroad as well as - at a minor extent - the students spending abroad periods shorter than the degree legal duration. This student mobility has not only a great potential for immediate individual growth, but also a long-term effect of fostering dialogue and reciprocal enrichment between home and guest communities, in a perspective of abundant and positive multiplier effects. Finally, learning from others' experiences acts as a powerful motor for reforms.

More concretely, globalisation and the need/right for students of recognition of their studies, when earned in other countries or regions, challenge higher education institutions. These last decades brought everywhere the paradigm shift from input-centred to output-centred education, aimed at fostering in the huge and steadily increasing mass of students, at all levels, key competences which lead not only to an essential personal growth, but which can also favour the establishment of viable civil societies, where knowledge has a serving role towards progress, access to jobs and wellbeing of all citizens.

This main challenge, namely to build a truly alive "knowledge society", was inflected in several more specific ones: matching the graduates' preparation to the needs of the job market; shifting the existing content-based degree courses to competence-based programmes; granting recognition of 
studies carried out abroad, identifying comparable learning outcomes for each programme or set of programmes and adopting a common and shared language (if not a common methodology); assessing the achievement of intended learning outcomes; and last but not least, the challenge of preparing higher education teachers to this epochal change in teaching. A common overarching challenge consists nowadays in identifying Quality Assurance (QA) Guidelines and assessment procedures for higher education institutions. In a global world, which calls for mass higher education and high levels of mobility, QA plays an unavoidable essential role to guarantee the monitoring, enhancing, and evaluation of systems.

In these years, some groups of dedicated people developed world-wide projects. The Tuning Academy and the huge AHELO (i.e. Assessment of Higher Education Learning Outcomes) project, launched years ago by the Organisation for Economic Co-operation and Development (OECD) and now concluded, are examples of good practices. Both initiatives brought awareness of the challenges to be faced as well as problems to be solved. Their actions often acted as incubators for new local initiatives.

In this Issue we present firstly the answers given so far by Latin America to the challenge of Quality Assurance, with an eye to the perspective involved in a possible forthcoming transition to a second generation of QA programs. We then present a "sub-regional" spinoff effect of the AHELO project, involving higher education institutions of Japan and Indonesia, willing to test, with an appropriate tool, the achieved learning outcomes of their students of mechanical engineering (master level). Finally, we present three articles from three African countries - Morocco, Ethiopia, and Tanzania - which deal with different facets of the complex challenge of the relationship between higher education and job market, here inflected in terms of job access, graduates' wages, employability and actual employment after a competence-based learning path. The last article in this Issue, focused on a specific aspect of the above landscape of answers to major challenges, investigates the relationship between algebraic competences with emotional intelligence.

The first article, proposed by Lemaitre, reviews firstly the socio-economical trends in the Latin American region and the specificity of that area, due to the strong sense of autonomy of the universities with respect to central governments and to the somewhat related lack of a national homogeneous university "system". On this basis, it gives an accurate description of the QA policies set up so far, at both country level and (sub-)regional level, reporting also the results of a study by CINDA-Centro Interuniversitario de Desarrollo, about the impact of QA practice on universities. Then, the article identifies the 
"challenges" for a new generation of QA practices in the area, which "taking into account the positive results of the first stage, is able to encourage and push institutions towards continuous improvement". Finally, the author makes suggestions, to the involved stakeholders, for policy actions aimed at setting up a "second generation of quality assurance processes".

The submission by Cross et al. reports about an application ${ }^{1}$ of the AHELO feasibility study to masters' level degree programs in the field of mechanical engineering. The article reports on the development of a test for measuring learning outcomes of first semester master students in mechanical engineering. The development occurred in Japan, among engineering faculty members, and, "through the collaborative process of test item development, scoring, and sharing of results", it yielded a true staff-development experience, renovating a common understanding of engineering learning outcomes. This was one of the great fruits of the process, as underlined by the authors. The item was tested in several Japanese universities (with 348 students). Subsequently, translated into English and Indonesian, the test was tried by 37 students at the Indonesia's Institut Teknologi Bandung.

The following three articles regard the relationship "university education versus employability", job market access, and actual employment. The article by Abaida et al. points out that "developing countries, particularly African countries, must show commitment towards and be prepared for the knowledge economy transition. This is an important challenge facing Africans in higher education institutions and policymakers". This article, focused on graduates of a Moroccan university (University Hassan I), investigates which kind of competences lead to high, medium or low wages. The statistical analysis of the data shows that generic competences and methodological skills lead to some benefits, while specialised competences lead to a less important effect. Empirical findings also suggest that the labour market rewards less specialised competences, and unlikely methodological

1 AHELO aimed at suggesting ways of "measuring" learning outcomes and focused on two subject areas (Economics and Engineering at Bachelor level) and on a third strand regarding Generic skills. Since its start, AHELO had strong links to Tuning, since the "OECD secretariat contracted the Tuning Association to undertake initial development work on expected/intended learning outcomes in the two disciplines selected for the AHELO Feasibility Study". This was "achieved through a Tuning-AHELO project", directly coordinated by the main Tuning experts. Japan participated in the engineering strand with its own expert (the first citation in the acknowledgements list accompanying this article). The feasibility of AHELO was then tested in 16 OECD countries as a whole, including Japan for civil engineering. There, the principal national coordinator was the third name in the present list of authors. Thus, the present article relies on quite a favourable background and on a fine group of AHELO original experts (also including the first name in the authors' list, who was an AHELO observer). 
and social competences are deemed more necessary compared to cognitive skills (theoretical knowledge). Finally, wages tend to decrease for those who are female and working in the private sector.

The article by Geressu examines an important aspect, i.e. the role of Technical and Vocational Education and Training (TVET) colleges in Ethiopia with regard to the extent at which their training approach is competence-based and to their effectiveness in preparing graduates for the labour market (employability) and in letting them enter the job market (employment). The research was based on: 1) questionnaire data collected among 461 respondents (instructors, automotive trainees, department heads, and graduates) and statistically analysed;2) semi structured interviews and focus group discussion involving industry owners, college deans, competencebased process owners and industry trainers. The results unveil poor awareness, on the side of the TVET college system, of the job market needs, both in terms of skills as well as of number of graduates, and, consequently, poor effectiveness in the competence-based preparation of their graduates, thus causing unemployment. In positive, the study recommends to promote a (now weak) "collaborative work culture among TVET colleges and industries".

The article by Ishengoma analyses, on the basis of existing evidence, the strong gap between the graduates' skills and the job market skills (61\% of graduates lack job skills according to a 2014 survey). The article suggests ways through which such a mismatch could be healed in the long-term, identifying in the Tuning methodology, as spread by Tuning Africa I \& II, "part of" a potentially solid solution. The author puts his working hypothesis to full academic scrutiny and debate, through a case study at the University of Dar es Salaam (UDSM)'s School of Education. Literature review, documents, reports and data collected among teachers and graduate students of the School through a questionnaire allow a deep analysis of the USDM teaching \& learning situation and - at large - of the situation regarding Tanzanian higher education. The role of Tuning methodology, as a most important driver for change/improvement, is confirmed, identifying as further challenges to be faced for a long-term solution the "poor teaching and learning conditions", the "shortage" of prepared senior teachers, the need for a "massive investment in teaching and learning resources".

The last article in the present Issue deals with algebraic competences, which are crucial in competence-based approaches and in knowledge societies. The study by Musonda investigates the relationship between the subject-specific "algebraic competences" with the "emotional intelligence" in a group of BSc first year students in Mathematics and Science Education 
at Copperbelt University in Zambia. The starting point of the study is that students performing well in mathematics at secondary school level, underperform in algebraic competences during the first university year. Among possible concurring factors, such as "learning resources, class sizes, lecturers' attitude, student's attitude, parental background" and even "cultural context", the author chooses to investigate the role of "emotional intelligence" as a possible positive factor in academic achievement, as suggested by some existing literature. The study does not find significant relationship between students' algebraic competences and their emotional intelligence in the sample of 107 involved students. Moreover, the study confirms that the emotional intelligence of female students has a much higher level than that of the male students.

As a conclusion, we like to underline the specificity and the added value, which are well illustrated by the above articles, of the regional and country level answers given to some of the main challenges facing global Higher Education nowadays. We welcome new contributions from other regions and countries on these very important challenges. We would like to share the certainty that reciprocal knowledge and fruitful comparisons, sharing and debates can yield further improvement at a global, regional, and country level. 


\title{
Editorial: Regional responses to Higher Education world-wide challenges
}

\author{
Luigi F. Donà dalle Rose \\ Editor
}

Anna Serbati

Assistant Editor

\section{Copyright}

Copyright for this article is retained by the Publisher. It is an Open Access material that is free for download, distribution, and or reuse in any medium only for non-commercial purposes; provided any applicable legislation is respected, the original work is properly cited, and any changes to the original are clearly indicated. 